\title{
HUBUNGAN PEMBERIAN ASI EKSKLUSIF DAN STIMULASI PSIKOSOSIAL DENGAN PERKEMBANGAN BALITA DI DESA MEUNASAH DAYAH KECAMATAN KOTA JUANG KABUPATEN BIREUEN
}

\section{The Relationship Of Exclusive Breastfeeding And Psychosocial Stimulation With The Development Of Children Under Five In Desa Meunasah Dayah Kecamatan Kota Juang Bireuen District}

\author{
Apriany Ramadhan Batubara*1, ${ }^{*}$ Mona $^{2}$ \\ 1. Dosen Akbid Munawarah, Jl. Sultan Iskandar Muda No. 18 Kota Juang, Bireuen 24251, Indonesia \\ 2. Mahasiswa Akbid Munawarah, Jl. Sultan Iskandar Muda No. 18 Kota Juang, Bireuen 24251, Indonesia \\ *Korespondensi Penulis : aprianyramadhanbatubara@gmail.com*1
}

\begin{abstract}
Abstrak
Latar Belakang : Balita merupakan masa yang sangat menentukan dalam proses tumbuh kembang dan menjadi dasar terbentuknya manusia seutuhnya. World Health Organitation (WHO) melaporkan bahwa 5-25\% anak anak usia prasekolah menderita disfungsi otak minor, termasuk gangguan perkembangan motorik halus. Anak yang mendapatkan ASI eksklusif selama 6 bulan atau lebih memiliki skor ASQ (Ages and Stages Questionnaire) lebih tinggi dengan nilai $\mathrm{p}(0,004)$ pada sektor motorik kasar dibandingkan dengan anak-anak yang tidak mendapatkan ASI eksklusif dengan nilai p (0,091). Tujuan : Untuk mengetahui hubungan pemberian ASI eksklusif dan stimulasi psikososial dengan perkembangan balita. Metode : Penelitian ini menggunakan survei analitik dengan pendekatan cross sectional. Penelitian dilaksanakan di Desa Meunasah Dayah Kecamatan Kota Juang Kabupaten Bireuen. Populasi dalam penelitian ini seluruh balita yang ada di Desa Meunasah Dayah sebanyak 316 orang dengan teknik pengambilan sampel secara random sampling dan pengambilan jumlah menggunakan rumus slovin sebanyak 76 balita. Data dianalisis secara univariat dan bivariat dengan menggunakan uji chi-Square pada taraf kepercayaan $95 \%(\mathrm{p}<0,05)$. Hasil : Berdasarkan hasil penelitian dengan uji statistik chi square diperoleh bahwa ada hubungan pemberian ASI eksklusif dengan perkembangan balita dengan nilai $\mathrm{p}$ value $(0,005)<\alpha(0,05)$. Serta ada hubungan stimulasi psikososial dengan perkembanan balita dengan nilai $\mathrm{p}$ value $(0,031)<\alpha(0,05)$. Kesimpulan : Ada hubungan pemberian ASI Eksklusif dan stimulasi psikososial dengan perkembangan balita di Desa Meunasah Dayah Kecamatan Kota Juang Kabupaten Bireuen. Diharapkan pada ibu untuk dapat meningkatkan bahan informasi tentang perkembangan balita dengan mengunjungi posyandu terdekat untuk mengetahui perkembangan balita.
\end{abstract}

\section{Kata kunci $\quad$ : ASI Eksklusif, Stimulasi Psikosoial, Perkembangan Balita}

\begin{abstract}
Background: Toddlers are a very decisive period in the process of growth and development and become the basis for the formation of a whole human being. The World Health Organitation (WHO) reports that 5-25\% of preschool children suffer from minor brain dysfunction, including impaired fine motor development. Children who were exclusively breastfed for 6 months or more had a higher ASQ (Ages and Stages Questionnaire) score with
\end{abstract}


Journal of Healthcare Technology and Medicine Vol. 6 No. 2 Oktober 2020

Universitas Ubudiyah Indonesia

e-ISSN : 2615-109X

a $p$ value (0.004) in the gross motor sector compared to children who were not exclusively breastfed with a p value (0.091). Objective: This is to determine the relationship between exclusive breastfeeding and psychosocial stimulation with the development of toddlers. Method: This study used an analytic survey with a cross sectional approach. The research was conducted in Meunasah Dayah Village, Kecamatan Kota Juang, Bireuen Regency. The population in this study were all toddlers in Meunasah Dayah Village as many as 316 people with a random sampling technique and 76 toddlers using the Slovin formula. Data were analyzed univariate and bivariate using the chi-Square test at the 95\% confidence level ( $p$ <0.05). Results: Based on the results of the study with the chi square statistical test, it was found that there was a relationship between exclusive breastfeeding and the development of children under five with a $p$ value (0.005) $<\alpha(0.05)$. And there is a relationship between psychosocial stimulation and the development of toddlers with $p$ value $(0.031)<\alpha(0.05)$.

Conclusion: There is a relationship between exclusive breastfeeding and psychosocial stimulation with the development of children under five in Desa Meunasah Dayah, Kecamatan Kota Juang, Kabupaten Bireuen. It is hoped that mothers can improve information materials about the development of toddlers by visiting the nearest posyandu to find out the development of toddlers

Keywords : Exclusive Breastfeeding, Psychosocial Stimulation, Toddler Development

\section{PENDAHULUAN}

Balita merupakan masa yang sangat menentukan dalam proses tumbuh kembang dan menjadi dasar terbentuknya manusia seutuhnya. Gangguan perkembangan anak akan berpengaruh terhadap masa depan anak sehingga sulit bersaing secara global (Profil Kesehatan RI, 2013).

Menurut United Nations Children's Fund (UNICEF) tahun 2011, didapatkan data masih tingginya angka kejadian gangguan pertumbuhan dan perkembangan pada anak usia balita khususnya gangguan perkembangan motorik didapatkan $(27,5 \%)$ atau 3 juta anak mengalami gangguan. World Health Organization (WHO) melaporkan bahwa 5-25\% anak anak usia prasekolah menderita disfungsi otak minor, termasuk gangguan perkembangan motorik halus (Widati, 2012).

Pada tahun 2013 secara nasional prevelensi kurus pada anak balita masih 12,1\%, yang artinya masalah kurus di Indonesia masih merupakan masalah kesehatan masyarakat yang serius. Depkes RI 2006 menyatakan bahwa 16\% balita Indonesia mengalami gangguan perkembangan, baik perkembangan motorik halus dan kasar, gangguan pendengaran, kecerdasan kurang dan keterlambatan bicara (Suryawan, 2010). 
Journal of Healthcare Technology and Medicine Vol. 6 No. 2 Oktober 2020

Universitas Ubudiyah Indonesia

e-ISSN : 2615-109X

Anak yang mendapatkan ASI eksklusif selama 6 bulan atau lebih memiliki skor ASQ (Ages and Stages Questionnaire) lebih tinggi pada sektor motorik kasar dibandingkan dengan anak-anak yang tidak mendapatkan ASI eksklusif. Sehingga dapat disimpulkan bahwa ASI eksklusif memiliki peran dalam tumbuh kembang anak, khususnya pada sektor motorik kasar. Pemberian ASI yang tidak eksklusif juga memberi dampak yang tidak baik bagi bayi.

Menurut World Health Organization (WHO), ASI eksklusif adalah pemberian ASI saja tanpa tambahan cairan lain baik susu formula, air putih, air jeruk, ataupun makanan tambahan lain sampai usia bayi 6 bulan. Sebelum mencapai usia 6 bulan sistem pencernaan bayi belum mampu berfungsi dengan sempurna, sehingga ia belum mampu mencerna makanan selain ASI (Marimbi, 2010).

Menyusui dapat meningkatkan probabilitas anak menjadi lebih sehat dan dapat mencegah terjadinya obesitas. Selain itu, menyusui selama 6 bulan atau lebih dapat meningkatkan perkembangan motorik kasar pada saat anak berusia 9 bulan. Masyarakat saat ini umumnya belum memahami bahwa keterlambatan perkembangan harus diidentifikasi dan ditangani sedini mungkin. Hal ini disebabkan karena kurangnya pengetahuan, sikap, kemampuan dan kepercayaan diri yang tinggi dalam merawat bayi khususnya dalam screening tumbuh kembang bayi.

Pemberian ASI tidak hanya berfungsi dalam memberikan nutrisi bagi bayi, tetapi juga sangat mempunyai arti dalam perkembangan anak karena seolah-olah hubungan anak ibu tidak terputus begitu dia dilahirkan kedunia. Demikian pula dengan pemberian ASI sedini mungkin segera setelah bayi lahir, merupakan stimulasi dini terhadap tumbuh kembang anak (Widayati, 2016).

Orang tua khususnya ibu merupakan lingkungan yang pertama dan utama bagi seorang bayi. Peran ibu sangat penting terutama sebagai agen kesehatan bagi anak dan keluarga dalam upaya memenuhi kebutuhan asah, asuh, asih pada bayi. Oleh karena itu, setiap ibu yang memiliki bayi memerlukan pengetahuan, sikap dan ketrampilan dalam screening tumbuh kembang bayi. Namun pada kenyataannya masyarakat saat ini belum memahami pentingnya screening perkembangan anak (Belfield, 2010).

Stimulasi psikososial merupakan faktor lingkungan psikososial dan kebutuhan asah yang mempengaruhi perkembangan bayi, dimana stimulasi psikososial adalah proses pembelajaran anak melalui pendidikan dan mengkoordinasikan otot-ototnya serta melibatkan 
Journal of Healthcare Technology and Medicine Vol. 6 No. 2 Oktober 2020

Universitas Ubudiyah Indonesia

e-ISSN : 2615-109X

perasaan emosi dan pikiran sehingga anak mendapat berbagai pengalaman hidup (Lestari, $2016)$.

Data Profil Kesehatan Provinsi Nanggroe Aceh Darussalam (2007), bayi yang mendapatkan ASI Eksklusif hanya 18.508 atau 16,8 \% dari sejumlah 110.301 bayi. Adapun Kabupaten dengan cakupan paling rendah adalah: (1) Nagan Raya, Gayo Lues, dan Kota Sabang, masing-masing 2\% bayi yang mendapatkan ASI Eksklusif. (2) Aceh Jaya, 66 bayi atau 3,6\%, (3) Aceh Timur, 327 bayi atau 3,9 \%; dan Aceh besar 629 bayi atau 9,25\% menempati urutan 8 setelah Aceh Utara, Aceh Selatan, Bener Meriah dan Bireuen.

Dari hasil survei awal yang dilakukan terhadap balita di Desa Meunasah Dayah Kecamatan Kota Juang jumlah keseluruhan balita yaitu 316 balita. Balita yang mendapatkan ASI eksklusif sebanyak 59 balita. Berdasarkan survei awal yang dilakukan peneliti dengan membagikan kuesioner, dari 10 balita yang diberikan ASI eksklusif, 2 diantaranya mengalami perkembangan yang terhambat dan dari 5 bayi yang tidak diberikan ASI Eksklusif, 3 diantaranya mengalami perkembangan yang terhambat.

Berdasarkan latar belakang diatas, peneliti tertarik untuk meneliti hubungan pemberian ASI eksklusif dan stimulasi psikososial dengan perkembangan balita di Desa Meunasah Dayah Kecamatan Kota Juang Kabupaten Bireuen.

\section{METODE PENELITIAN}

Penelitian ini menggunakan metode penelitian survei analitik. Survei analitik merupakan penelitian yang mencoba menggali bagaimana dan mengapa fenomena itu terjadi, kemudian melakukan analisis dinamika kolerasi antara fenomena, baik antara faktor resiko (independen) dan faktor efek (dependen). yang mana menggunakan pendekatan cross sectional untuk mengetahui hubungan pemberian ASI Eksklusif dan stimulasi psikososial dengan perkembangan balita.

Penelitian dilaksanakan di Desa Meunasah Dayah Kecamatan Kota Juang Kabupaten Bireuen. Waktu penelitian dilaksanakan pada bulan Agustus 2020. Populasi dalam penelitian ini adalah seluruh balita yang berumur 6-60 bulan di Desa Meunasah Dayah Kecamatan Kota Juang Kabupaten Bireuen sebanyak 316 orang. Teknik pengambilan sampel dalam penelitian ini secara random sampling dan pengambilan jumlah menggunakan rumus slovin sebanyak 76 balita. 
Journal of Healthcare Technology and Medicine Vol. 6 No. 2 Oktober 2020

Universitas Ubudiyah Indonesia

e-ISSN : 2615-109X

\section{HASIL PENELITIAN}

Analisis Univariat : Berdasarkan tabel 1 dapat dilihat bahwa dari 76 balita (100\%), yang diberikan ASI EKsklusif sebanyak 49 balita (64,5\%) dan yang tidak diberikan ASI Ekslusif sebanyak 27 balita (35,5\%). Pada stimulasi psikososial, dari 76 balita (100\%), yang mendapatkan stimulasi psikososial baik sebanyak 28 balita (36,9\%), stimulasi psikososial cukup sebanyak 21 balita $(27,6 \%)$ dan stimulasi psikososial kurang sebanyak 27 balita (35,5\%). Dan hasil dari perkembangan balita, didapatkan dari 76 balita (100\%), yang mengalami perkembangan terhambat sebanyak 14 balita $(18,4 \%)$ dan yang tidak terhambat dalam perkembangan sebanyak 62 balita $(81,6 \%)$.

Tabel 1. Distribusi Frekuensi pemberian ASI Eksklusif dan Stimulasi Psikososial dan perkembangan balita di Desa Meunasah Dayah Kecamatan Kota Juang Kabupaten Bireuen.

\begin{tabular}{ccc}
\hline Analisa Univariat & \multicolumn{2}{c}{ Jumlah } \\
\cline { 2 - 3 } & f & \% \\
\hline ASI Eksklusif & 49 & 64,5 \\
Diberikan & 27 & 35,5 \\
Tidak Diberikan & & \\
Stimulasi Psikososial & 28 & 36,9 \\
Baik & 21 & 27,6 \\
Cukup & 27 & 35,5 \\
Kurang & & \\
Perkembangan Balita & 14 & 18,4 \\
Terhambat & 62 & 81,6 \\
Tidak Terhambat & & \\
\hline
\end{tabular}

Analisis Bivariat : Berdasarkan tabel 2 dapat dilihat bahwa tabulasi silang antara pemberian ASI Eksklusif dengan perkembangan balita di Desa Meunasah Dayah Kecamatan Kota Juang Kabupaten Bireuen, dapat diketahui bahwa dari 76 balita (100\%) sebanyak 49 balita $(64,5 \%)$ yang diberikan ASI Eksklusif mengalami perkembangan terhambat sebanyak 4 balita $(5,3 \%)$ dan perkembangan tidak terhambat sebanyak 45 balita $(59,2 \%)$. Dari 27 balita $(35,5 \%)$ yang tidak diberikan ASI Eksklusif, balita yang mengalami perkembangan terhambat sebanyak 10 balita $(13,2 \%)$ dan perkembangan tidak terhambat sebanyak 17 balita $(22,4 \%)$. Dari hasil uji statistik Chi-square dengan tingkat kepercayaan 95\% $(\alpha=0,05)$ hasil perhitungan menunjukkan nilai $\mathrm{p}(0,005)<\mathrm{p}$ value $(0,05)$ berarti $\mathrm{H}_{0}$ ditolak dan Ha diterima. Dengan demikian ada hubungan pemberian ASI eksklusif dengan perkembangan balita di Desa Meunasah Dayah Kecamatan Kota Juang Kabupaten Bireuen. Tabulasi silang antara stimulasi psikososial dengan perkembangan balita di Desa Meunasah Dayah Kecamatan Kota 
Journal of Healthcare Technology and Medicine Vol. 6 No. 2 Oktober 2020

Universitas Ubudiyah Indonesia

e-ISSN : 2615-109X

Juang Kabupaten bireuen, dapat diketahui dari 76 balita (100\%) sebanyak 28 balita (36,9\%) yang mendapatkan stimulasi psikososial baik mengalami perkembangan terhambat sebanyak 4 balita (5,3\%) dan perkembangan tidak terhambat sebanyak 24 balita (31,6\%). Dari 21 balita $(27,6 \%)$ yang mendapatkan stimulasi psikososial cukup, balita yang mengalami perkembangan terhambat sebanyak 1 balita $(1,3 \%)$ dan perkembangan tidak terhambat sebanyak 20 balita (26,3\%). Dan dari 27 balita (35,5\%) yang mendapatkan stimulasi psikososial kurang, balita yang mengalami perkembangan terhambat sebanyak 9 balita $(11,8 \%)$ dan perkembangan tidak terhambat sebanyak 18 balita $(23,7 \%)$. Dari hasil uji statistik Chi-square dengan tingkat kepercayaan 95\% $(\alpha=0,05)$ hasil perhitungan menunjukkan nilai $\mathrm{p}(0,031)<\mathrm{p}$ value $(0,05)$ berarti $\mathrm{H}_{0}$ ditolak dan Ha diterima. Dengan demikian ada hubungan antara pemberian stimulasi psikososial dengan perkembangan balita di Desa Meunasah Dayah Kecamatan Kota Juang Kabupaten Bireuen.

Tabel 2. Hubungan Pemberian ASI Eksklusif dan Stimulasi Psikososial dengan Perkembangan Balita di Desa Meunasah Dayah Kecamatan Kota Juang Kabupaten Bireuen

\begin{tabular}{cccccccc}
\hline & \multicolumn{7}{c}{ Perkembangan Balita } \\
\cline { 2 - 9 } Analisa Bivariat & Terhambat & Tidak Terhambat & $\sum$ & p-value \\
\cline { 2 - 9 } & f & \% & f & \% & F & \% & \\
\hline ASI Eksklusif & & & & & & & \\
Diberikan & 4 & 5,3 & 45 & 59,2 & 49 & 64,5 & 0,005 \\
Tidak Diberikan & 10 & 13,2 & 17 & 22,4 & 27 & 35,5 & \\
\hline Stimulasi Psikososial & & & & & & & \multirow{2}{*}{0,031} \\
Baik & 4 & 5,3 & 24 & 31,6 & 28 & 36,8 & \\
Cukup & 1 & 1,3 & 20 & 26,3 & 21 & 27,6 & \\
Kurang & 9 & 11,8 & 18 & 23,7 & 27 & 35,5 & \\
\hline
\end{tabular}

\section{PEMBAHASAN}

Hubungan Pemberian ASI Eksklusif dengan Perkembangan Balita : Berdasarkan hasil penelitian menunjukkan bahwa tabulasi silang antara pemberian ASI Eksklusid denagn Perkembangan Balita di Desa Meunasah Dayah, dapat diketahui bahwa dari dari 76 balita (100\%) sebanyak 49 balita (64,5\%) yang diberikan ASI Eksklusif mengalami perkembangan terhambat sebanyak 4 balita $(5,3 \%)$ dan perkembangan tidak terhambat sebanyak 45 balita $(59,2 \%)$. Dari 27 balita (35,5\%) yang tidak diberikan ASI Eksklusif, balita yang mengalami perkembangan terhambat sebanyak 10 balita $(13,2 \%)$ dan perkembangan tidak terhambat sebanyak 17 balita (22,4\%). Dari hasil uji statistik Chi-square dengan tingkat kepercayaan 
Journal of Healthcare Technology and Medicine Vol. 6 No. 2 Oktober 2020

Universitas Ubudiyah Indonesia

e-ISSN : 2615-109X

95\% $(\alpha=0,05)$ hasil perhitungan menunjukkan nilai $\mathrm{p}(0,005)<\mathrm{p}$ value $(0,05)$ berarti $\mathrm{H}_{0}$ ditolak dan Ha diterima. Dengan demikian ada hubungan pemberian ASI eksklusif dengan perkembangan balita di Desa Meunasah Dayah Kecamatan Kota Juang Kabupaten Bireuen.

ASI merupakan makanan pertama, utama, dan terbaik bagi bayi, bersifat ilmiah. ASI eksklusif adalah bayi hanya diberi ASI selama 6 bulan tanpa tambahan makanan cairan lain, seperti susu formula, jeruk, madu, air teh, dan air putih, serta tanpa tambahan makanan padat, seperti pisang, bubur susu, biscuit, bubur nasi, dan nasi tim, kecuali vitamin, mineral, dan obat (Prasetyono, 2009).

Banyak faktor yang mempengaruhi pemberian ASI eksklusif pada bayi usia 0-6 bulan. Kegagalan ASI eksklusif adalah karena faktor predisposisi yaitu pengetahuan dan pengalaman ibu yang kurang dan faktor pemungkin penting yang menyebabkan terjadinya kegagalan adalah karena ibu tidak difasilitasi melalui IMD. Hasil penelitian menunjukan bahwa pengetahuan dan pengalaman ibu sangat penting dalam menentukan pemberian ASI eksklusif pada bayinya.

Pemberian ASI eksklusif memiliki pengaruh yang signifikan terhadap perkembangan bayi dengan nilai OR 6,000, dimana ASI mengandung zat kimia bioaktif yang berperan penting untuk perkembangan otak, yang artinya ibu yang memberikan ASI tidak eksklusif beresiko 6 kali memiliki bayi yang dugaan keterlambatan perkembangan dibandingkan dengan ibu yang memberikan ASI eksklusif (Escamilla, 2005).

Menurut asumsi peneliti pemberian ASI eksklusif memegang peranan penting dalam memengaruhi perkembangan balita. Dapat dilihat dari hasil penelitian balita yang diberikan ASI eksklusif cenderung memiliki perkembangan yang normal, dan balita yang tidak diberikan ASI eksklusif cenderung memiliki perkembangan yang terhambat. Hal tersebut disebabkan karena ASI mengandung banyak nutrisi, Komposisi ASI bersifat spesifik pada tiap ibu, berubah dan berbeda dari waktu ke waktu yang disesuaikan dengan kebutuhan bayi saat itu. Bayi yang mendapat ASI eksklusif akan lebih sehat dan lebih jarang sakit, karena ASI mengandung berbagai zat kekebalan. Pemberian ASI eksklusif juga berkaitan dengan status ibu, dimana seorang ibu yang bekerja diluar cenderung tidak memberikan ASI eksklusif kepada bayinya karena tempat ibu bekerja tidak terjangkau untuk pulang memberikan ASI kepada bayinya setiap 2 jam sekali dan ibu tidak memerah ASI, sehingga pada saat ibu bekerja, bayi harus diberikan susu formula sampai ibunya pulang bekerja. 
Journal of Healthcare Technology and Medicine Vol. 6 No. 2 Oktober 2020

Universitas Ubudiyah Indonesia

e-ISSN : 2615-109X

Tingkat pendidikan ibu juga berkaitan dengan pemberian ASI eksklusif pada bayi. Semakin tinggi tingkat pemahaman ibu mengenai pentingnya memberikan ASI eksklusif pada bayi, maka semakin banyak ibu yang memberikan ASI eksklusif pada bayinya.

Hubungan Stimulasi Psikososial dengan Perkembangan Balita : Berdasarkan hasil penelitian menunjukkan bahwa tabulasi silang antara stimulasi psikososial dengan perkembangan balita di desa Meunasah Dayah, dapat diketahui bahwa dari 76 balita (100\%) sebanyak 28 balita $(36,9 \%)$ yang mendapatkan stimulasi psikososial baik mengalami perkembangan terhambat sebanyak 4 balita $(5,3 \%)$ dan perkembangan tidak terhambat sebanyak 24 balita (31,6\%). Dari 21 balita $(27,6 \%)$ yang mendapatkan stimulasi psikososial cukup, balita yang mengalami perkembangan terhambat sebanyak 1 balita $(1,3 \%)$ dan perkembangan tidak terhambat sebanyak 20 balita (26,3\%). Dan dari 27 balita $(35,5 \%)$ yang mendapatkan stimulasi psikososial kurang, balita yang mengalami perkembangan terhambat sebanyak 9 balita $(11,8 \%)$ dan perkembangan tidak terhambat sebanyak 18 balita $(23,7 \%)$. Dari hasil uji statistik Chi-square dengan tingkat kepercayaan 95\% $(\alpha=0,05)$ hasil perhitungan menunjukkan nilai $\mathrm{p}(0,031)<\mathrm{p}$ value $(0,05)$ berarti $\mathrm{H}_{0}$ ditolak dan Ha diterima. Dengan demikian ada hubungan antara pemberian stimulasi psikososial dengan perkembangan balita di Desa Meunasah Dayah Kecamatan Kota Juang Kabupaten Bireuen.

Menurut IDAI (2010) stimulasi adalah kegiatan merangsang kemampuan dasar anak usia 0-6 tahun agar anak dapat tumbuh dan berkembang secara optimal. Setiap anak perlu mendapatkan stimulasi teratur sedini mungkin secara terus menerus pada setiap kesempatan. Stimulasi merupakan hal yang sangat penting dalam perkembangan anak.

Kemampuan anak dalam personal sosial sangat dipengaruhi oleh faktor lingkungan, adanya faktor lingkungan baik internal maupun eksternal, yang mana cara seorang anak dalam berinteraksi dengan orang tua akan berpengaruh dengan interaksi anak di luar rumah karena hubungan yang hangat dengan orang lain, seperti ayah, ibu, teman sebaya, dan sebagainya akan berpengaruh besar terhadap emosi, sosial, dan intelektual anak. Perkembangan personal sosial meliputi berbagai kemampuan yang dikelompokkan sebagai kebiasaan, kepribadian, watak, dan emosi (Soetjiningsih dan Ranuh, 2013).

Stimulasi merupakan hal yang penting untuk perkembangan anak, dalam stimulasi juga membutuhkan alat bantu sederhana sesuai tingkat usia perkembangan, anak yang 
Journal of Healthcare Technology and Medicine Vol. 6 No. 2 Oktober 2020

Universitas Ubudiyah Indonesia

e-ISSN : 2615-109X

mendapat stimulasi yang teratur dan terarah akan lebih cepat berkembang dibandingkan dengan anak yang kurang mendapat stimulasi. (Soetjiningsih dan Ranuh, 2013).

Perkembangan anak yang normal disebabkan oleh pemberian stimulasi yang dilakukan oleh orang tua balita. Anak yang mendapatkan stimulasi yang terarah dan teratur akan lebih cepat berkembang dibandingkan dengan anak yang tidak tahu atau kurang mendapat stimulasi. Stimulasi mental (asah) dapat menunjang perkembangan mental psikososial anak yang meliputi kecerdasan, kemandirian, kreativitas anak, kepribadian, dan produktifitas (Soetjiningsih dan Ranuh, 2013).

Menurut asumsi peneliti, pemberian stimulasi psikososial pada balita sangat berpengaruh terhadap perkembangan balita. Karena rangsangan psikososial yang baik berkaitan dengan kesehatan anak sehingga secara tidak langsung dapat memengaruhi status perkembangan anak. Kualitas stimulasi psikososial ini sendiri tergantung dari keadaan keluarga, masyarakat serta lingkungan. Pemberian stimulasi psikososial juga dapat membantu anak untuk mencapai tingkat perkembangan sesuai dengan usianya.

\section{KESIMPULAN}

Berdasarkan hasil penelitian maka dapat disimpulkan sebagai berikut: ada hubungan pemberian ASI Eksklusif dan stimulasi psikososial dengan perkembangan balita di Desa Meunasah Dayah Kecamatan Kota Juang Kabupaten Bireuen.

\section{SARAN}

Diharapkan kepada seluruh ibu yang memiliki balita agar lebih aktif melakukan stimulasi sosial dan memberikan ASI Eksklusif mengingat pentingnya hal tersebut dalam perkembangan balita, dan diharapkan agar kepada pemberi pelayanan kesehatan di Desa Meunasah Dayah agar lebih aktif memberi penyuluhan kepada seluruh warga tentang pentingnya pemberian ASI Eksklusif dan stimulasi sosial sehingga perkembangan balita di desa tersebut semakin membaik.

\section{DAFTAR PUSTAKA}

Febriana, 2015. Hubungan Pemberian ASI Eksklusif dengan Perkembangan Bayi Usia 9-12 Bulan di Puskesmas Gamping I Sleman. Yogyakarta. 
Journal of Healthcare Technology and Medicine Vol. 6 No. 2 Oktober 2020

Universitas Ubudiyah Indonesia

e-ISSN : 2615-109X

Imam M, 2016. Panduan Penyusunan Karya Tulis Ilmiah Bidang Kesehatan Menggunakan Metode Ilmiah. CitaPustaka Media Perintis, Bandung.

Intani T, 2019. Hubungan Pemberian ASI Eksklusif dan Stimulasi Psikososial dengan Perkembangan Bayi Berumur 6-12 Bulan. Jurnal Kesehatan Andalas. Vol 8 No 1.

Jannah N, 2013. Asuhan Kebidanan Ibu Nifas. AR-Ruzz Media, Yogyakarta.

Khoirunnisa E, 2010. Asuhan Kebidanan Neonatus, Bayi, dan Anak Balita. Nuha Medika, Yogyakarta.

Muflihatin S, 2018. Deteksi Dini Perkembangan Balita dengan Metode DDST di Posyandu Wilayah Kerja Puskesmas Juanda Samarinda. Jurnal Endurance . Vol 3 No 2.

Mulyanti S, 2017. Hubungan Stimulasi Psikososial dengan Perkembangan Anak Usia 3-72 Bulan di Wilayah Kerja Puskesmas Lubuk Begalung Padang. Jurnal kesehatan andalas. Vol 6 No 2.

Muslihatun W, 2012. Asuhan neonatus, bayi dan balita. Fitramaya, Yogyakarta.

Notoatmodjo S, 2010. Metodologi Penelitian Kesehatan. Rineka Cipta, Jakarta

Prasetyono D, 2009. Buku pintar ASI eksklusif. Diva Press, Yogyakarta.

Widayati W, 2016. Hubungan Pemberian ASI Terhadap Perkembangan Bayi Usia 6-12 Bulan. Jurnal Ilmiah Kesehatan. Vol 5 No 9. 